\title{
Diversifying the options for interacting with patients
}

\section{Edward H Wagner}

\section{Shared medical appointments or group visits have proven to be a promising way of providing planned care to older and chronically ill patients with two powerful added attractions-patient peer support and improved practice efficiency}

M any commentators over the years have lamented the "tyranny" of the brief office visit. The urgency of patient problems, the short duration of office visits and the tendency of clinicians to talk far more than they listen leaves little time for human interaction, much less preventive care and routine chronic illness management. Rushed, problemoriented visits have been implicated as a major reason that roughly one-half of Americans with chronic illness are not receiving effective care. ${ }^{1}$ In addition to negative impacts on the process of care, substantial percentages of American sicker adults report that their doctors do not answer their important questions $(24 \%)$, do not tell them about their treatment or ask their opinions (50\%), and do not make treatment goals clear $(27 \%) .^{2}$ These data help explain the observation that chronically ill individuals report lower satisfaction with care than do others and that, among individuals with a specific condition such as diabetes, satisfaction declines with increasing severity of illness. ${ }^{3}$ Respondents in other developed nations report somewhat better communication, but not by much.

Patients are not the only ones frustrated. The daily grind of a relentless series of these brief encounters contributes to the growing dissatisfaction of American primary care doctors, who, unlike some of their European counterparts, rarely see patients in other settings such as in their homes or even in the hospital. The enthusiasm for new models of primary care, based on the Chronic Care and Medical Home models in the U.S. ${ }^{45}$ is, in part, driven by frustration with this style of practice and its deleterious impacts on the doctor-patient relationship, professional well-being, and quality of care. A long day comprising mostly short office visits with often frustrating outcomes has been called the "treadmill" by Tom Bodenheimer, ${ }^{6}$ and treadmill practice appears to be harmful to the health of patients, especially the chronically ill, and to the well-being of practitioners.

One healthy response to the deficiencies and demands of the treadmill is to diversify the ways of communicating with patients. This was a recommendation of the Institute of Medicine's report, "Crossing the Quality Chasm". Diversification is not simply to reduce stress for the practice team. A range of communication modalities enables practices to tailor interaction methods to the clinical needs and preferences of patients and their families. For example, multiple studies have demonstrated the effectiveness of telephone follow-up, which now can include electronic monitoring of patient status. ${ }^{8}$ Recent studies are suggesting that e-mail may be another attractive option for interacting with patients remotely. ${ }^{9}$ Kilo describes a high performing practice designed around the needs of patients in which $80 \%$ of their interactions with patients are by telephone or e-mail. ${ }^{10}$

But electronic communication cannot totally replace face-to-face interactions if we are to achieve effective clinical management and continuous healing relationships. $^{7}$ If brief, problem-focused office visits are not meeting the needs of many patients, especially the chronically ill, how might they be improved? One common characteristic of acute care visits is that they are, almost by definition, unplanned. The agenda is determined by the urgency of the presenting problem, the time available and the priorities of the clinician. If urgency is high, time is short, and the priority is to resolve the acute problem, the quieter needs of prevention and chronic illness management often are put off for another day. In contrast, prenatal, well-child and preventive care visits have clear agendas, which is to assure that patients receive recommended services in a timely way. Planned or structured chronic care visits attempt to do the same for the chronically ill. ${ }^{11}{ }^{12}$
Planned visits are focused on meeting patient chronic care needs. These include providing recommended assessments and preventive interventions, adjusting clinical management, reviewing and supporting patient self-management, and arranging follow-up. Non-physician staff tend to play major roles in planned visits from overseeing their organisation to providing various services by standing orders.

Planned visits can be conducted with individual patients or with groups of patients. Shared medical appointments or group visits as nicely described by Kirsh and colleagues in this issue ${ }^{13}$ (see page 349) have proven in several studies to be a promising way of providing planned care to older and chronically ill patients with two powerful added attractions-patient peer support and improved practice efficiency. ${ }^{14}$ Group visits have now been implemented in a wide variety of practice settings and with diverse patient populations, and lessons have been learnt. First, many practitioners and their patients fail to appreciate that shared medical appointments or group visits are just that - an alternative way of conducting routine office visits for patients accepting of a group setting. They are not one-time special events or patient education classes, although they often have important educational components. They are medical appointments conducted in a group context. Second, the words "group" or "shared" indicate that patient participation and communication are central. The interactions among patients are the most compelling feature of group visits for most patients, but helping providers avoid dominating the agenda and limiting patient to patient communication requires training and ongoing coaching. Third, generally less than one-half of patients invited to attend group visits accept the invitation, and attendance tends to be spotty. Reasonable hypotheses are that receptivity and attendance will be better in practices that enthusiastically endorse the approach, and among groups that meet at regular intervals and are highly interactive.

Despite the interest in group visits, and their mention in the new models of primary care, rigorous evaluation has been limited to a few randomised trials targeting high-utilising older patients and those with diabetes, headaches and cardiovascular disease. ${ }^{14}$ Evaluations to date suggest that group visits regularly increase patient satisfaction and improve care processes, but impacts on outcomes such as HbAlc levels have been mixed. Kirsh and colleagues achieved impressive reductions in HbAlc, LDL cholesterol and systolic blood pressure compared with non-randomised controls. Their positive 
impacts on disease control measures, in contrast to other diabetes group-visit trials, may reflect the fact that the Cleveland VA group implemented shared medical appointments as an integral element of a major quality improvement effort to redesign their practice in accord with the Chronic Care Model.

In addition to the advantages to patients mentioned above, the routine use of group visits can increase office efficiency with reasonable group sizes (12-20 patients/ group). In most settings with which we have worked, practices have been able to bill insurers for a brief visit with each group member if they have a brief personal conversation with each patient (not necessarily in private) and document the findings in the chart. Once they get the hang of it, most physicians value this new role for themselves and the different perspectives it gives them about their patients. ${ }^{15}$ Clearly, there is much more to learn about group visits and their effectiveness, but evidence to date suggests that they should be considered a valuable option for older and chronically ill patients.

\section{ACKNOWLEDGEMENTS}

This work was supported by grant \#053022 from the Robert Wood Johnson Foundation.

Qual Saf Health Care 2007; 16:322-323.

doi: 10.1136/qshc.2007.022970

Correspondence to: Edward H Wagner, MacColl Institute for Healthcare Innovation, Center for Health Studies, Group Health, 1730 Minor Avenue, Suite 1290, Seattle, WA 98101, USA; wagner.e@ghc.org

\section{REFERENCES}

1 Wagner EH, Austin BT, Von Korff M. Organizing care for patients with chronic illness. Milbank $Q$ 1996;74:511-44.

2 Davis K, Schoen C, Schoenbaum SC, et al. Mirror, mirror on the wall: an update on the quality of American health care through the patient's lens. New York: The Commonwealth Fund, 2006.

3 Kerr EA, Smith DM, Kaplan SH, et al. The association between three different measures of health status and satisfaction among patients with diabetes. Med Care Res Rev 2003;60:158-77.

4 Future of Family Medicine Project Leadership Committee. The future of family medicine: a collaborative project of the family medicine community. Ann Fam Med 2004;2(suppl 1):S3-32.

5 American College of Physicians. Policy monograph. The advanced medical home: A patient-centered, physician-guided model of health care. Philadelphia: American College of Physicians, 2006.
6 Bodenheimer T. Primary care-will it survive? N Engl J Med 2006;355:861-4.

7 Committee on Quality of Health Care in America, Institute of Medicine. Crossing the quality chasm: a new health system for the 21 st century. Washington, DC: National Academy Press, 2001.

8 Wasson J, Gaudette C, Whaley F, et al. Telephone care as a substitute for routine clinic follow-up. JAMA 1992;267:1788-93.

9 Leong SL, Gingrich D, Lewis PR, et al. Enhancing doctor-patient communication using email: a pilot study. J Am Board Fam Pract 2005; 18:180-8.

10 Kilo CM. Transforming care: medical practice design and information technology. Health Aff (Millwood) 2005;24:1296-301.

11 Wagner EH, Austin BT, Davis C, et al. Improving chronic illness care: translating evidence into action. Health Aff (Millwood) 2001;20:64-78.

12 Bodenheimer T. Planned visits to help patients selfmanage chronic conditions. Am Fam Physician 2005:72: 1454-6.

13 Kirsh S, Watts S, Pascuzzi K, et al. Shared medical appointments based on the chronic care model: a quality improvement project to address the challenges of patients with diabetes with high cardiovascular risk. Qual Saf Health Care 2007; 16:349-53.

14 Jaber R, Braksmajer A, Trilling JS. Group visits: a qualitative review of current research. J Am Board Fam Med 2006;19:276-90.

15 Beck A, Scott J, Williams P, et al. A randomized trial of group outpatient visits for chronically ill older HMO members: the Cooperative Health Care Clinic. J Am Geriatr Soc 1997;45:543-9.

\section{Quality Forum Abstracts}

Next year will see the publication of the Quality Forum 2008 abstracts published online with the April issue of Quality \& Safety in Health Care. They will be freely available online at http:// qshc.bmj.com and will be fully citable.

The Quality Forum is taking place on 23-25 April 2008, at the Le Palais des Congrès de Paris, Paris. For more information please visit http://www.quality.bmipg.com/. 